\title{
A TERMINOLOGIA: UM INSTRUMENTO AO SERVIÇO DA INOVAÇÃO PEDAGÓGICA NO ESPAÇO EUROPEU DO ENSINO SUPERIOR
}

\section{TERMINOLOGY: A TOOL FOR PEDAGOGICAL INNOVATION IN THE EUROPEAN HIGHER EDUCATION}

\author{
Rosa Maria Fréjaville* \\ Universidade Jean Monnet, Saint-Étienne, França
}

\begin{abstract}
Resumo: Neste artigo, apresentam-se algumas reflexões sobre a importância da Terminologia em formacçōes multilíngues especializadas no âmbito do ensino das línguas aplicadas no ensino superior, com especial incidência no sistema de ensino superior francês. Se tivermos em conta a políitica linguística de construção do Espaço Europeu do Ensino Superior (EEES) e os diversos contributos que desde 0 século XX a Terminologia tem vindo a oferecer não só ao sistema de comunicação especializada, aos sistemas informáticos inteligentes, mas também a diversas profissões (mediadores linguísticos e culturais, tradutores) e novas necessidades (multilinguismo e interculturalidade), verificaremos que 0 ensino (teórico e prótico) da Terminologia nas formaç̦ées universitárias se torna um elemento incontornável. A sociedade do conhecimento não se pode concretizar sem a aquisição da competência terminológica que se manifesta, tradicionalmente, pela utilização de terminologias e de discursos especializados em variadas situações e em differentes contextos de produção/recepcão comunicativa.
\end{abstract}

Palavras-chave: Competência terminológica; ensino superior,línguas aplicadas; sociedade do conhecimento; QECRL.

\begin{abstract}
This article presents some reflections on the importance of Terminology as a theoretical framework, methodological tool and a vital resource in specialized multilingual training in the teaching of Applied Languages in Higher Education with a particular focus on the French High Education System. If we take into account the linguistic policy for the construction of the European Higher Education Area and the various contributions that Terminology has made since the $20^{\text {th }}$ century not only to the specialized communication system, to the intelligent computer systems, but also to several professions (linguistic and cultural mediators, translators) and new needs (multilingualism and interculturality), we can see that the teaching (both theoretical and practical) of Terminology in university courses is becoming an essential element. The knowledge society cannot be achieved without terminological competence acquisition, which is traditionally manifested by the use of terminologies and specialized discourses in a variety of situations and in different contexts of communicative production/reception.
\end{abstract}

Keywords: Terminological Competence; Applied Languages; Higher Education; Knowledge Society; CEFR.

* Professora doutora da Universidade Jean Monnet - UJM, Saint-Étienne, França; rosa-maria.frejaville@wanadoo.fr

htrp://dx.doi.org/10.11606/issn.2236-4242.v33ilp167-185 
Linha D’Água (Online), São Paulo, v. 33, n. 1, p. 167-185, jan.-abr. 2020

\section{Introdução}

A Terminologia, uma prática muito antiga, torna-se no século XX uma nova ciência e disciplina indispensável para a difusão da inovação e a análise dos domínios de especialidade, nomeadamente, na organização dos sistemas terminológicos e na sua adequação temático-terminológica em situação bilíngue e/ou multilíngue.

Várias escolas e abordagens da Terminologia vieram contribuir para a reflexão e a institucionalização de processos e normas (por exemplo, a Organização Internacional de Normalização - ISO); assim como a construção de ferramentas indispensáveis para a análise e a organização de terminologias e sua extração, a comunicação especializada e a resolução eficaz de problemas ligados ao multilinguismo e à multiculturalidade. Referimo-nos assim muito particularmente às correntes e períodos que mais do que oporem, se completam. Entre outras, podemos citar: a Teoria Geral da Terminologia (Wüster), a Teoria Comunicativa da Terminologia (Cabré), a Socioterminologia (Gaudin), a Linguística de Corpus (Condamines), a Ontoterminologia (Rastier, Depecker, Roche), a Terminologia Cultural (Dikidiri). Segundo Humbley, citado em Zanola (2018, p. 26), a evolução da Terminologia enquanto disciplina fez-se em três tempos: nascimento e afirmação da Teoria Geral da Terminologia, a existência do sistema da dimensão fraseológica e discursiva da terminologia e, por fim, a tomada de consciência da variação linguística no seio das terminologias.

Teresa Zanola (2018) considera que a Terminologia ocupa um lugar de destaque na construção do pensamento europeu, exercendo um papel fundamental na difusão do conhecimento que é hoje tributário de situações multilíngues e multiculturais: "Il ruolo fondamentale della terminologia può essere colto appieno ripercorrendo alcune tappe della costruzione dei saperi e della trasmissione e comunicazione della conoscenza, fondamentali nelle scenario culturale europeo" (Zanola, 2018, p. 9)

Tendo, pois, a Terminologia e a sua importância para a construção da "sociedade do saber" nomeadamente a valorização do conhecimento no mercado de trabalho como núcleo da nossa reflexão, dividimos este trabalho em três partes. Numa primeira parte, apresentaremos aspectos importantes da política linguística da União Europeia. Em seguida, descreveremos o papel da Terminologia nas

FRÉJAVILLE, R. M. A Terminologia: um instrumento ao serviço da inovação pedagógica no Espaço Europeu do Ensino Superior 
Linha D'Água (Online), São Paulo, v. 33, n. 1, p. 167-185, jan.-abr. 2020

formações de ensino superior e sua ação no que concerne à harmonização e à internacionalização das universidades. Mostraremos, por fim, a relação entre a metodologia terminológica e o ensino das línguas estrangeiras, no caso concreto dos cursos de Línguas Estrangeiras Aplicada; e a sua relevância no âmbito do Quadro Europeu Comum de Referência para as Línguas (QECRL) na aquisição de competências plurilingues e pluriculturais.

\section{Política linguística da União Europeia: vasto programa para uma globali- zação positiva}

Os acontecimentos históricos que marcaram o fim do século XX integram-se já no longo processo de globalização: o novo paradigma que criou a aproximação e a interligação entre estados e sociedades a todos os níveis (económico, social, político, cultural). A ampliação da diversidade cultural, a mobilidade de pessoas no mundo, a comunicação instantânea e o desenvolvimento da internet são vetores de novas políticas e de uma nova visão do mundo.

Nesse sentido, a ação da União Europeia é exemplar ao defender e ao promover o multilinguismo e o multiculturalismo como maneira de impedir a imposição de uma "língua global" e o imperialismo de uma cultura. Não esqueçamos que uma política linguística é, na sua relação com a globalização, a ferramenta por excelência de gestão, difusão e promoção das línguas.

Os principais objetivos que orientam a ação da União Europeia são: a defesa da diversidade linguística com a promoção do plurilinguismo, da mobilidade estudantil e profissional; a promoção da utilização de diferentes línguas no mundo do trabalho; a valorização do diálogo intercultural, do desenvolvimento da sociedade europeia do conhecimento e das relações internacionais. Na verdade, após a construção do espaço econômico e do programa de mobilidade de pessoas, o grande objetivo do programa da União Europeia é hoje a criação do cidadão europeu, indivíduo caraterizado pela excelente competência profissional, plurilingue e pluricultural. O multilinguismo é assim um fator de construção da cidadania europeia, de promoção da internacionalização da sua economia e culturas.

FRÉJAVILLE, R. M. A Terminologia: um instrumento ao serviço da inovação pedagógica no Espaço Europeu do Ensino Superior 
Tudo isto supõe, por um lado, que cada estado terá de promover a terminologia em suas próprias línguas o que torna a terminologia um fator de coesão social e elemento tutelar da diversidade cultural e linguística. Por outro lado, é o multilinguismo que alimenta a internacionalização e a transferência de conhecimentos especializados. Como afirma Teresa Zanola (2018, p. 90): "Le esigenze della comunicazione specialistica e accademica, dell'internazionalizzazione e del trasferimento delle conoscenze specialistiche non hanno spinte monolingui, seguono piuttosto le esigenze delle realtà comunicative"1.

Como tem, então, agido a União Europeia face ao novo desafio da globalização?

O papel da Universidade é deveras importante, razão pela qual a União Europeia tem investido na construção do espaço europeu do ensino superior (EEES)2. Em que consiste esta construção? Em primeiro lugar, numa nova política de educação e de formação com base no multilinguismo e no multiculturalismo, cujos exemplos mais visíveis são os programas de mobilidade estudantil e profissional, tais como o ERASMUS +. Em segundo lugar, as universidades têm uma grande responsabilidade nesse processo. Assim, para além da sua tradicional função - veicular o conhecimento -, as universidades têm vindo a transformar os seus cursos superiores adaptando-os às novas necessidades societais: a relação com o mundo do trabalho, as formações direcionadas para a aquisição de competências, a aprendizagem das línguas em situação comunicativa, multilíngue e multicultural com a aquisição de novas competências de comunicação em linguagens especializadas,

1 "As necessidades da comunicação especializada e acadêmica, da internacionalização e da transmissão do conhecimento especializado não têm limites monolingues, preferido seguir as exigências das realidades de comunicação" (tradução nossa)

2 Eis algumas datas importantes para a construção do espaço europeu do ensino superior: 1987, Programa de mobilidade ERASMUS; 1997, Convenção de Lisboa (reconhecimento dos diplomas); 1998, Declaração da Sorbonne para a harmonização da arquitetura do ensino superior na Europa (sistema comum de diplomas e nascimento do conceito de EEES); 1999, Processo de Bolonha (sistema comum de créditos ECTS, 29 países implicados, concertação de políticas para a criação do EEES, emergência de uma Europa do conhecimento); entre 2001 a 2012, várias conferências ministeriais (criação do EEES); 2018, conferência ministerial europeia em Paris de 47 ministros do Ensino Superior (programa para a promoção de práticas pedagógicas inovadoras e inclusão de novos públicos); modalidades de programas de futuro e meios no ES com a reestruturação das universidades: os célebres IDEX (Initiative d'excellence, relativa à atribuição de financiamentos às Universidades)

FRÉJAVILLE, R. M. A Terminologia: um instrumento ao serviço da inovação pedagógica no Espaço Europeu do Ensino Superior 
Linha D’Água (Online), São Paulo, v. 33, n. 1, p. 167-185, jan.-abr. 2020

em técnicas interculturais e de mediação. Nesse sentido, a universidade europeia moderna tem de formar cidadãos europeus com mobilidade territorial, profissionais adaptáveis às novas emergências, altamente qualificados com saberes-fazer pluridisciplinares e transversais.

O Espaço Europeu de Ensino Superior é, finalmente, um espaço multilíngue e multicultural no qual o processo de aprendizagem do plurilinguismo, da pluriculturalidade, da intercompreensão, da interculturalidade e da mediação são a chave do seu sucesso, podendo tornar-se um modelo para a harmonização dos diversos modelos universitários existentes em diferentes países e mesmo dentro dos mesmos países. Referimo-nos, aqui, à coexistência de três sistemas que correspondem a três conceitos diferentes com disparidade no plano estrutural, de gestão, de práticas e de géneros discursivos. Para Lessard e Bourdoncle (2002) estamos perante três tipos de universidades. Em primeiro lugar, a universidade liberal de tradição anglo-saxónica idealizada por Henry Newman em 1852, na qual o mais importante é a aquisição de uma certa cultura geral, em total incompatibilidade com a formação profissional. A universidade da investigação é o segundo modelo, de tradição alemã, com grande enfâse na investigação científica e na difusão do conhecimento com integração no meio profissional, privilegiando-se a análise e o espírito crítico a favor da inovação e da aquisição de bons conhecimentos e aptidões profissionais; pois só o professor investigador tem aptidão para construir e transmitir o conhecimento. A universidade de serviço, de inspiração norte-americana, é o último modelo, que vê na cultura geral e na ciência simples ferramentas ao serviço do progresso social, com uma visão muito pragmática do saber como meio de evolução de toda a sociedade.

Saliente-se que os desafios lançados para a concretização do EEES não têm correspondido totalmente aos anseios da União Europeia no que diz respeito à internacionalização das universidades; um elemento da política linguística europeia com objetivos bem definidos a atingir e que são: a visibilidade, a inovação, o reconhecimento, a excelência, a competitividade, a excecionalidade e a qualidade. Muito caminho falta, pois, percorrer.

A evolução do ensino superior europeu tem vindo, apesar de tudo, a harmonizar-se graças aos programas da União Europeia, mas muitos obstáculos ainda

FRÉJAVILLE, R. M. A Terminologia: um instrumento ao serviço da inovação pedagógica no Espaço Europeu do Ensino Superior 
Linha D’Água (Online), São Paulo, v. 33, n. 1, p. 167-185, jan.-abr. 2020

persistem devido, como vimos, às diferentes filosofias, estruturas e práticas universitárias. Num trabalho que tivemos a oportunidade de realizar sobre a situação dos Cursos superiores de Património em alguns países da União Europeia, as questões aqui abordadas são analisadas em detalhe:

Les nouveaux métiers liés au domaine du Patrimoine sont de plus en plus nombreux. Ils supposent de nouvelles formations universitaires au sein desquelles les langues devraient acquérir un rôle de premier plan. Le multilinguisme apparaît ici comme un élément essentiel au service de la promotion du patrimoine mondial et de sa préservation. Cependant, on constate que le concept même de $\mathrm{Pa}-$ trimoine se trouve au cœur d'un véritable paradoxe : universel s'il en faut, le terme implique une immense diversité culturelle ainsi que la prise en compte d'un grand nombre de spécificités territoriales qui rendent le concept de patrimoine souvent très flou (FRÉJAVILLE et al., 2017, p. 1)3

Perante a tendência ainda muito marcada de preservar um ensino superior que teve certamente a sua época de glória, no nosso trabalho concluímos que um curso como o de Património só poderá ter uma verdadeira visibilidade internacional, um reconhecimento científico e profissional forte se esse for capaz de se adaptar a novas emergências, tais como as investigações e práticas ligadas a novos conceitos federadores como a patrimonialização; e a novos modelos de conhecimento orientados pela pluridisciplinaridade e pela transversalidade. No final do nosso trabalho concluímos que a Terminologia poderá servir de ponte, de elemento essencial para a organização dos conhecimentos e da relação entre áreas formadoras de competências:

3 "As novas profissões ligadas ao domínio do Património são cada vez mais numerosas e exigem a criação de novas formações universitárias no seio das quais as línguas deveriam ocupar o primeiro lugar. $\bigcirc$ multilinguismo aparece aqui como um elemento fundamental ao serviço da promoção do património mundial e da sua preservação. No entanto, verifica-se que até o conceito de património se encontra no centro de um verdadeiro paradoxo: universal, se necessário, o termo implica uma imensa diversidade cultural assim como um grande número de particularidades territoriais que conferem ao conceito de património um caráter frequentemente opaco" (tradução nossa)

FRÉJAVILLE, R. M. A Terminologia: um instrumento ao serviço da inovação pedagógica no Espaço Europeu do Ensino Superior 
Linha D'Água (Online), São Paulo, v. 33, n. 1, p. 167-185, jan.-abr. 2020

Il existe bel et bien un système terminologique du domaine du Patrimoine, avec des velléités propres à chaque pays. L'internationalisation et la formation en Patrimoine sera effective si la formation au multilinguisme devient un de ses éléments-clés et si l'enseignement de la Terminologie encore très présente en Sciences du Langage reprend sa place en tant que discipline complémentaire, voire fondamentale, dans les formations universitaires qui appellent à la pluriculturalité, à la transversalité et à l'interdisciplinarité. Tout cela permettra un nouveau paradigme (FRÉJAVILLE et al. 2017, p. 16) ${ }^{4}$

Não podemos deixar de concluir este capítulo sem referir que todos os avanços teóricos e práticos que a Terminologia produziu têm hoje grande repercussão em setores como as indústrias da língua, os sistemas de regulamentação e de normalização internacionais, novas ferramentas ligadas às novas tecnologias da informação e à inteligência artificial, sem esquecer os benefícios para o trabalho dos profissionais da tradução, da mediação e do ensino moderno das línguas.

Apesar de tudo isso, a disciplina de Terminologia que durante os anos 1990 fazia parte dos cursos superiores de Humanidades em muitas universidades francesas desapareceu quase completamente dos programas de formação em línguas aplicadas. Citando ainda o caso francês, só algumas universidades propõem formações em Terminologia para dar resposta à procura de profissionais plurilingues e peritos em indústrias da língua, por exemplo. Das universidades que ainda apostam no ensino da Terminologia contam-se: a Universidade Paris 3 (no terceiro ano de licenciatura, na variante de Tradução Especializada, com as disciplinas Terminologia e Lexicologia em língua A e B; no mestrado em Língua e Sociedades -variante Tratamento da Informação, Linguística, Tradução (TILT) e no mestrado em Línguas, Literatura e Civilizações) e a Universidade de Toulon (Linguística Aplicada, Introdução à Linguística de Corpus, Linguística e Tratamento Automático

\footnotetext{
4 "Existe claramente um sistema terminológico do domínio do Património com caraterísticas próprias a cada país. A internacionalização e a formação na área de Património serão bemsucedidas se a formação em multilinguismo for um dos seus elementos-chave e se o ensino da Terminologia, com forte presença ainda nas Ciências da Linguagem, voltar a ser uma disciplina complementar ou mesmo até fundamental, nos cursos universitários que privilegiam a pluriculturalidade, a transversalidade e a interdisciplinaridade. E assim poderá surgir $m$ novo paradigma" (tradução nossa)
}

FRÉJAVILLE, R. M. A Terminologia: um instrumento ao serviço da inovação pedagógica no Espaço Europeu do Ensino Superior 
Linha D’Água (Online), São Paulo, v. 33, n. 1, p. 167-185, jan.-abr. 2020

das Linguas, Procura de Informação e Web Semântico, Terminologia). A Universidade de Lyon com o seu centro de investigação vocacionado para a Terminologia e a Tradução ainda resiste, pelo menos, na área da investigação, visto que as disciplinas relacionadas com a Terminologia há muito desapareceram dos cursos de Humanidades, nomeadamente, no curso de Línguas Estrangeiras Aplicadas.

\section{A Terminologia no Ensino Superior: uma necessidade, uma força para a internacionalização das universidades}

A Terminologia nos curricula do Ensino Superior poderá vir a ser uma excelente ferramenta metodológica e pedagógica para a formação em competências plurilingues e pluriculturais de estudantes universitários, qualquer que seja a sua área de formação. A Terminologia poderá assim responder aos desafios lançados pelo processo de Bolonha, contribuindo para a internacionalização das universidades europeias e para os novos desafios de diálogo e de mediação intercultural.

Também o conceito de profissionalização tem vindo a ser integrado ao percurso acadêmico do aluno, como por exemplo: unidades curriculares consagradas à inserção profissional, estágios nacionais e internacionais em empresas e organismos, serviços universitários vocacionados para a pesquisa/inovação e empreendedorismo.

A inserção profissional nos diferentes cursos universitários está hoje plenamente adotada em muitas universidades francesas. A que se deve um tal empenhamento? A União Europeia quer que as suas universidades tenham um papel relevante na construção da cidadania europeia e na promoção da empregabilidade no seu espaço; tornando-se assim necessário dotar os seus cidadãos das competências pessoais e profissionais que possam contribuir para a criação da comunidade multilíngue e pluricultural a que aspira hoje a Europa.

Numa perspetiva socioprofissional, a Terminologia para além de contribuir para a organização e a difusão do conhecimento, tem um papel importante na comunicação especializada em contextos socioprofissionais. Ela pode contribuir para a formação de profissionais altamente competentes e aptos a negociarem em contextos multilíngues, em situações de intercompreensão e de interculturalidade.

FRÉJAVILLE, R. M. A Terminologia: um instrumento ao serviço da inovação pedagógica no Espaço Europeu do Ensino Superior 
Linha D’Água (Online), São Paulo, v. 33, n. 1, p. 167-185, jan.-abr. 2020

A inovação e a qualidade são realmente um dos principais objetivos que guiam o processo de transformação da Universidade no século XXI e abrangem o sistema de organização, as formações, os métodos e as posturas. Nesse contexto de inovação cada vez mais exigente, a Terminologia permite uma dupla harmonização: ao nível interno em ligação com as transformações inevitáveis em curso no seio das universidades tanto do ponto de vista pedagógico como estrutural; ao nível externo com vista a uma harmonização e a uma concertação entre universidades europeias, numa primeira fase.

Se a Terminologia está praticamente ausente da universidade francesa, nada impede que pela via da sua metodologia possa integrar plenamente formações, por exemplo, que estarão sempre dependentes do conhecimento das linguagens de especialidade, da aprendizagem de línguas estrangeiras, de técnicas de tratamento de informação, de métodos de mediação e de negociação. Podemos considerar que na verdade a Terminologia e o trabalho terminológico abrangem todos os setores do conhecimento.

\section{Terminologia: contribuições metodológicas e relações interdisciplinares para o ensino das línguas}

A União Europeia não poupa esforços ao propor meios para harmonizar os diferentes sistemas educativos nacionais e propor um novo paradigma de aprendizagem das línguas e culturas, para favorecer a existência de um espaço europeu plurilingue e pluricultural.

Nesse sentido torna-se necessário referir a importância que tem hoje o Quadro Europeu Comum de Referência para as Línguas (Aprender, Ensinar, Avaliar) do serviço de educação da Direção de participação democrática da Direção Geral da Democracia (DGII) do Conselho da Europa. O Quadro está organizado em 9 capítulos que cobrem os seguintes aspetos: contexto político e educacional, abordagem, níveis de referência, utilização da língua e utilizador da língua, ensino e aprendizagem das línguas, a função das tarefas no ensino e aprendizagem de línguas, diversificação linguística e currículo, avaliação.

FRÉJAVILLE, R. M. A Terminologia: um instrumento ao serviço da inovação pedagógica no Espaço Europeu do Ensino Superior 
Linha D’Água (Online), São Paulo, v. 33, n. 1, p. 167-185, jan.-abr. 2020

Como indicado no site, o Quadro foi publicado em 2001 com o objetivo de fornecer uma base transparente, coerente e o mais exaustiva possível para a elaboração de programas de línguas, de diretivas para os currículos, materiais de ensino e de aprendizagem, avaliação de competências em línguas estrangeiras. O quadro é utilizado nos 47 estados membros do Conselho da Europa e em outros continentes 5 .

Um novo volume complementar foi publicado em 2018 com novos descritores, numa perspetiva de adaptar a aprendizagem e o ensino das línguas às novas realidades e aos desafios da política linguística da União Europeia. Nessa nova versão são incluídas a competência plurilingue e pluricultural, a mediação (tipologia: mediação de textos, mediação de conceitos, mediação da comunicação para estabelecimento de um espaço pluricultural; e respetivas estratégias de mediação). O QECRL substitui o modelo tradicional das quatro competências - ouvir, falar, ler, escrever- anacrônicos face às novas necessidades comunicativas que contemplam as situações de interatividade, o diálogo intercultural, a intercompreensão e a mediação necessárias para a coconstrução do sentido. As situações comunicativas são apresentadas segundo quatro modos de comunicação: recepção, produção, interação, mediação.

Qual é a importância do QECRL no âmbito da política linguística europeia? Trata-se na verdade de uma base comum para a elaboração de programas de línguas vivas, referenciais, exames, manuais, etc. Faz a descrição e enumeração dos conhecimentos e competências que o aluno deve adquirir. Define os níveis de competências para medida da progressão na aprendizagem.

Quais são em síntese os seus principais objetivos? São desenvolver um ensino plurilingue e pluricultural; promover um ensino das línguas de qualidade e uma Europa de cidadãos plurilingues e abertos à interculturalidade; facilitar a comunicação entre europeus de línguas maternas diferentes; favorecer a mobilidade, a intercompreensão e a cooperação na Europa.

O Quadro faz parte do vasto projeto que quer reformar o sistema de ensino das línguas vivas com harmonização internacional.

A mudança de paradigma anunciada no Quadro é notória e coloca claramente o aluno no centro da sua aprendizagem.

5 Ver https://www.coe.int/fr/web/common-european-framework-reference-languages

FRÉJAVILLE, R. M. A Terminologia: um instrumento ao serviço da inovação pedagógica no Espaço Europeu do Ensino Superior 
Linha D'Água (Online), São Paulo, v. 33, n. 1, p. 167-185, jan.-abr. 2020

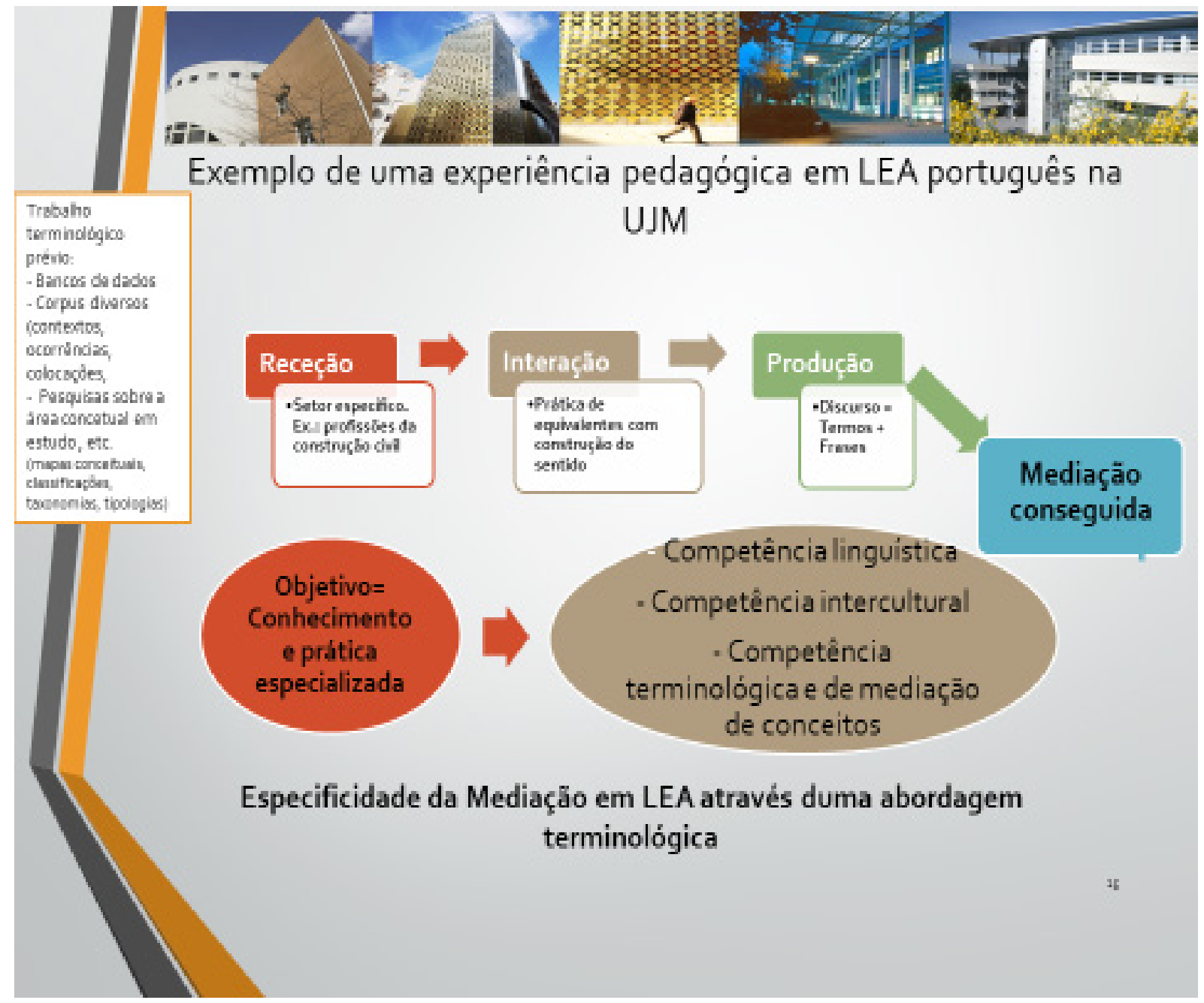

Figura 1: Quadro com uma experiência pedagógica a partir dos quatro modos de comunicação para a aprendizagem de português como língua estrangeira ${ }^{6}$.

$\mathrm{Na}$ figura 1 está retratada uma nova experiência de ensino-aprendizagem levada a cabo em aulas de cadeiras de português do curso de Línguas Estrangeiras Aplicadas (variante inglês-português) na Universidade Jean Monnet, na França, desde 2011. A experiência tem como pressuposto que o aluno é o ator da sua própria aprendizagem. Nesse contexto, o ensino-aprendizagem estrutura-se em torno de metodologias ativas para a aquisição da competência linguística e comunicativa

6 Quadro apresentado pela autora durante a vídeo conferência subordinado ao título Inovação pedagógica e avaliação? A velha nova questão no ensino superior, in Primer Congreso Internacional y Cuarto Nacional, Paradigma de la Evaluación y Innovación de la Educación en el Nível Médio Superior, Benemérita Universidad Autónoma de Puebla, 17 de outubro de 2019

FRÉJAVILLE, R. M. A Terminologia: um instrumento ao serviço da inovação pedagógica no Espaço Europeu do Ensino Superior 
Linha D’Água (Online), São Paulo, v. 33, n. 1, p. 167-185, jan.-abr. 2020

em português (atividades de receção, de interação e de produção salientadas no QECRL) e concomitantemente em técnicas muito ligadas ao trabalho terminológico (utilização, por exemplo, e conforme as necessidades, das perspetivas onomasiológica e semasiológica na construção dos saberes $\left.{ }^{7}\right)$. Nesse âmbito, a mediação ${ }^{8}$ tem um papel de relevo. As atividades de mediação (tais como a tradução e a identificação de equivalentes) na aprendizagem de uma língua estrangeira contribuem para a aquisição da competência plurilingue e intercultural.

O curso de LEA deve formar profissionais qualificados com competências comunicativas em línguas especializadas, competências plurilingues e pluriculturais, competências de mediação, capazes também de se adaptarem à emergência de novas profissões e de novos projetos profissionais qualificantes.

É importante salientar que os cursos de LEA apareceram por volta dos anos 1970 e foram, à partida, acompanhados na sua evolução pela Associação Nacional de Línguas Estrangeiras Aplicadas (ANLEA), criada em 1972 para representar, promover e federar os cursos de LEA na França:

Actuellement 50 universités françaises comportent une UFR, un département ou un parcours en Langues Etrangères Appliquées en premier cycle (licence), et en second cycle (master). Certaines de ces filières proposent également une poursuite d'étude en troisième cycle. L'ANLEA œuvre pour le développement de la formation et de la recherche en LEA, pour leur valorisation auprès des acteurs institutionnels et économiques, et pour l'insertion professionnelle de ses diplômés. Elle soutient également le développement international des formations en LEA, soit par le biais d'échanges, soit par le montage de filières LEA à l'étranger. (ANLEA) ${ }^{9}$

7 Cf. trabalho terminológico prévio da Figura 1.

8 Inicialmente um termo do domínio jurídico que significava o meio pelo qual se podiam resolver conflitos entre duas partes.

9 "Cinquenta universidades francesas possuem atualmente uma UFR (Unidade de Formação e de Investigação), um departamento ou um curso de primeiro e segundo ciclos (licenciatura e mestrado) em Línguas Estrangeiras Aplicadas. Alguns destes cursos propõem também uma pósgraduação. A ANLEA (Associação Nacional de Línguas Estrangeiras Aplicadas) promove o desenvolvimento da formação e da investigação em LEA, a sua valorização junto dos organismos institucionais e económicos: e a inserção profissional dos estudantes formados. Apoia de igual modo o desenvolvimento internacional dos cursos de LEA por via de intercâmbios e por via da criação de cursos de IEA no estrangeiro." (tradução nossa). Texto retirado de "Bienvenue sur le site officiel de l' Association Nationale des Langues Etrangères Appliquées". Disponível em:

FRÉJAVILLE, R. M. A Terminologia: um instrumento ao serviço da inovação pedagógica no Espaço Europeu do Ensino Superior 
Linha D’Água (Online), São Paulo, v. 33, n. 1, p. 167-185, jan.-abr. 2020

A AILEA, ramo internacional da ANLEA, age a favor da internacionalização das formações LEA promovendo acordos e criação do curso no estrangeiro, respondendo assim positivamente aos desígnios da construção do EEES e à inserção profissional dos cidadãos europeus (taxa de 80\% de empregabilidade segundo dados da ANLEA). A sua função é descrita no site dando ênfase a:

La formation universitaire en LEA, Langues Etrangères Appliquées, prépare soit aux métiers du commerce international, des relations internationales et des relations interculturelles, soit à ceux de la traduction spécialisée. Son caractère pluridisciplinaire confère une place importante aux langues étrangères tout en respectant l'équilibre entre les langues et d'autres disciplines telles que le droit, la gestion, l'économie, la communication, la terminologie, à titre d'exemples. (ANLEA) ${ }^{10}$

Por conseguinte, essa formação associa o domínio das línguas (pelo menos duas línguas em pé de igualdade) e das ciências humanas às disciplinas ditas de "aplicação", nomeadamente o direito e a economia (1/3 da formação), numa arquitetura cara às recomendações de Bolonha: o sistema LMD (Licence, Master, Doctorat), o sistema ECT, a mobilidade dos estudantes, os estágios em empresas e os diplomas conjuntos. O corpo docente é composto por acadêmicos e profissionais.

Considera-se que as línguas A e B não têm uma relação de língua dominante e língua dominada e devem possuir um número semelhante de créditos europeus. Os diplomas LEA são cursos que beneficiam igualmente de um grande número de programas de mobilidade (ERASMUS+ e outros acordos bilaterais), de orientação e de integração profissional (por exemplo, o Projeto Pessoal e Profissional, os módulos de integração e, até mesmo, encontros com profissionais para obtenção

https://anlea.org/. Acesso em: 13 de jun de 2019.

10 "O curso superior de LEA, Línguas Estrangeiras Aplicadas, forma o aluno para trabalhar nas áreas do comércio internacional, das relações internacionais, das relações interculturais ou das profissões ligadas à tradução especializada. O seu caráter pluridisciplinar oferece um lugar importante às línguas estrangeiras, respeitando o equilíbrio entre as línguas e outras disciplinas como, por exemplo, o Direito, a Gestão, a Economia, a Comunicação, a Terminologia. " (tradução nossa). Texto retirado de "Formation LEA. La filière Langues Etrangères Appliquées". Disponível em: https://anlea.org/formation-lea/. Acesso em: 13 de jun de 2019.

FRÉJAVILLE, R. M. A Terminologia: um instrumento ao serviço da inovação pedagógica no Espaço Europeu do Ensino Superior 
Linha D’Água (Online), São Paulo, v. 33, n. 1, p. 167-185, jan.-abr. 2020

de estágios curriculares). Quanto à composição do curso de Licenciatura, a sua estrutura é a seguinte:

- Licenciatura $1^{\circ}$ ano, seis grandes unidades de ensino: uma EU1 - Metodologia e ferramentas documentais e digitais; uma EU2 Línguas (língua francesa e língua C), uma EU3 - Cultura Geral; uma EU4 - Referências Históricas; uma EU5 - Abordagem de uma disciplina - Língua A e B (Língua, língua comercial, tradução, civilização); uma EU6- suplemento disciplinar (domínios cultura jurídica e cultura económica).

- Licenciatura $2^{\circ}$ ano, quatro unidades de ensino: uma UE1 - Unidade de ensino transversal (Projeto Pessoal e Profissional [PPP], TIC, língua C), uma UE2 - Formação específica adicional (por exemplo, economia empresarial, direito empresarial); uma UE3 - Língua A (língua, linguagem empresarial, tradução, civilização); uma UE4 - Língua B (língua, linguagem empresarial, tradução, civilização).

- $\quad$ Licenciatura $2^{\circ}$ ano, quatro unidades de ensino: uma UE1 - Língua A (Língua, Tradução/Interpretação, Cultura); uma UE2 - Língua B (Língua, Tradução/Interpretação, Cultura); uma UE3 - Formação específica adicional (Introdução ao comércio internacional, por exemplo); uma UE4 - Unidade de ensino transversal (TIC, Língua C, disciplinas de créditos avulsos); uma UE5 no segundo semestre - Integração profissional e estágio curricular)

O aluno que se matrícula na variante inglês-português na Universidade Jean Monnet é em geral um aluno sem qualquer aprendizagem da língua portuguesa no liceu. Chega, pois, à Universidade com um nível B2 em inglês e um nível Pré-A1 em português. O nosso projeto pedagógico é, pois, levá-lo rapidamente a falar em português corrente, a utilizar o português de especialidade (por exemplo, português comercial) em situação profissional, a discursar sobre conteúdos culturais e a progressivamente adquirir os mecanismos e as técnicas para realizar ações de plurilinguismo pela intercompreensão e pela mediação. Torna-se, pois, evidente que nesse contexto tenhamos optado por seguir as orientações do Quadro Europeu Comum de Referência para as Línguas com as necessárias estratégias de

FRÉJAVILLE, R. M. A Terminologia: um instrumento ao serviço da inovação pedagógica no Espaço Europeu do Ensino Superior 
Linha D’Água (Online), São Paulo, v. 33, n. 1, p. 167-185, jan.-abr. 2020

orientação e a adoção de metodologias terminológicas, conforme se pode verificar na Figura 2 infra.

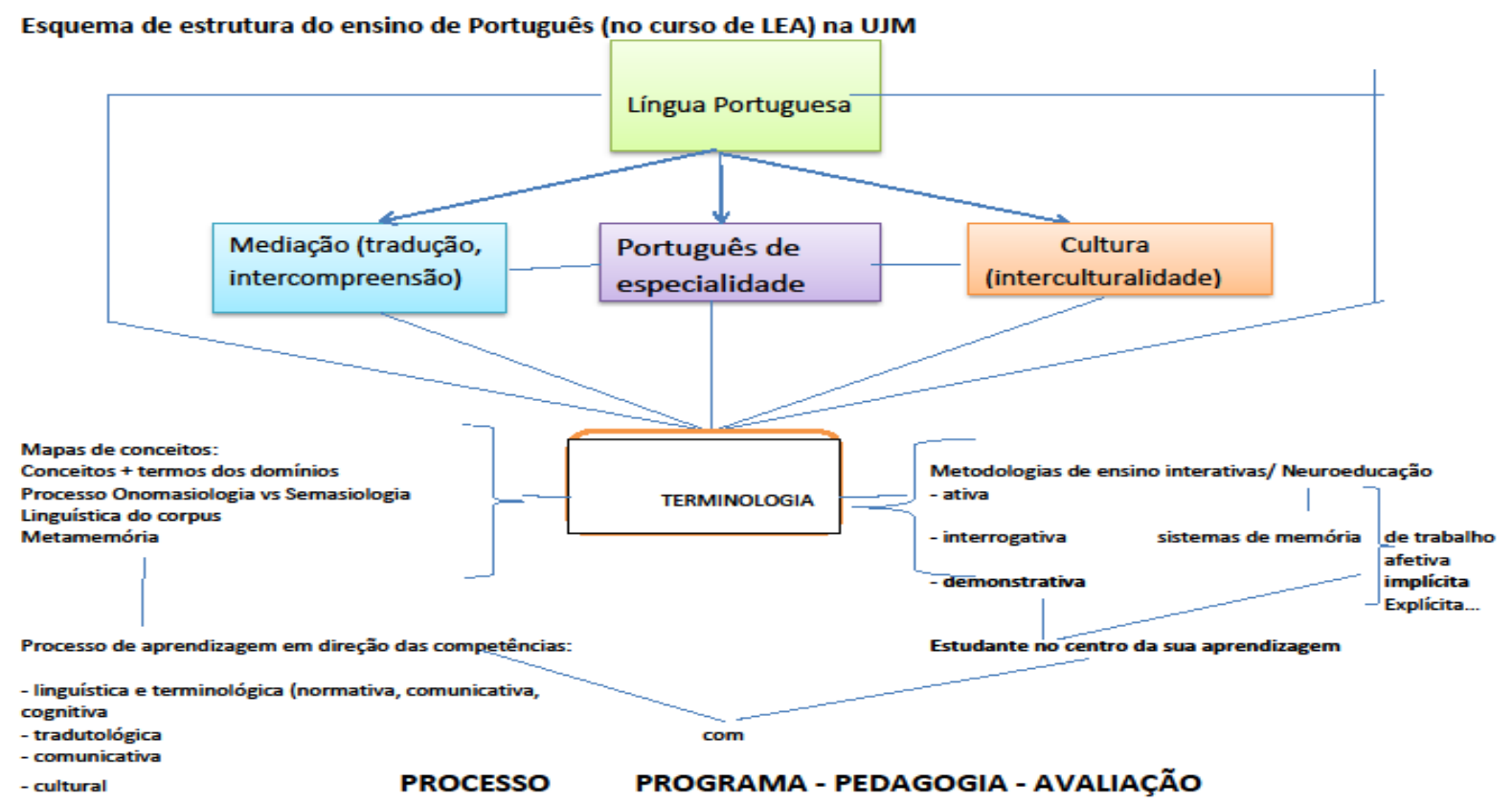

Figura 2: Esquema de metodologia de ensino das disciplinas de português em prática na UJM ${ }^{11}$

Os descritores do QECRL indicam claramente a necessidade de uma proposta de aprendizagem das línguas em ação utilizando mecanismos para a realização de atividades discursivas, em diversas situações do quotidiano e em diversos domínios de ação (público, pessoal, educativo, profissional).

A recepção abrange ações de comunicação centradas na compreensão. Nessa primeira fase o trabalho terminológico acompanha a aquisição, sempre em situação comunicativa (interação professor/aluno e aluno/aluno), de um dado conjunto conceitual. A abordagem onomasiológica é aqui privilegiada na medida em que o aluno vai compreender os conceitos que vão identificar os termos adequados e, assim, em autonomia, estabelecer a terminologia mais eficaz.

11 Quadro apresentado pela autora durante a vídeo conferência subordinado ao título Inovação pedagógica e avaliação? A velha nova questão no ensino superior, in Primer Congreso Internacional y Cuarto Nacional, Paradigma de la Evaluación y Innovación de la Educación en el Nível Médio Superior, Benemérita Universidad Autónoma de Puebla, 17 de outubro de 2019.

FRÉJAVILLE, R. M. A Terminologia: um instrumento ao serviço da inovação pedagógica no Espaço Europeu do Ensino Superior 
Linha D’Água (Online), São Paulo, v. 33, n. 1, p. 167-185, jan.-abr. 2020

A fase da produção incita à co-construção de sentidos pela via, nomeadamente, de comparação de línguas (a materna e a estrangeira): busca de equivalentes, construções discursivas com aplicação de ocorrências e de colocações. A utilização de ferramentas terminológicas é largamente ensinada e aplicada (bancos de dados como IATE, softwares de extração de terminologias como AntCon, etc.), assim como a abordagem semasiológica para identificação das terminologias, a explicitação de traços conceituais, a utilização das terminologias na comunicação especializada

As fases de interação e de mediação completam o processo de aquisição de uma língua estrangeira e a sua utilização com clareza e coesão terminológica: "L'attenzione alla precisione terminologica deve caratterizzare la preparazione professionale di tutti: il rapporto chiaro fra la nomenclatura e l'ogetto e/o il concetto sono la garanzia di una comunicazione corretta, rispettosa dell'altro, competente e desperta" (ZANOLA, 2018, p. 104) ${ }^{12}$.

Realça-se que se finalmente a terminologia não é ensinada como disciplina teórica independente, ela encontra-se presente em todas as fases da aprendizagem da língua em suas diferentes abordagens. $O$ trabalho realizado em português é um dos trabalhos pioneiros que põe em destaque o projeto EEES e integra o trabalho terminológico em todas as fases de aquisição de uma língua e/ ou de uma especialidade.

Resta salientar a contribuição dada pelos diferentes sistemas de memória para o êxito do processo programa - pedagogia - avaliação. A área das neurociências cognitivas oferece pistas de que podem ajudar a produzir a interação com o ambiente do sujeito/aluno valorizando nesse a vontade e a motivação. Elas estão efetivamente ligadas aos mecanismos de memória e facilitam a aprendizagem com repercussões positivas no desenvolvimento cerebral.

A memória constrói-se com conceitos, imagens, aprendizagens e costumes, necessita de um constante aperfeiçoamento e é imprescindível num trabalho de síntese e de assimilação. Trata-se, pois, de uma função cerebral que permite a codificação, a recolha e a recuperação de informação. Existem vários tipos de memória que poderão ser sabiamente utilizados no ensino e na aprendizagem. Assim, as

12 Trad. A.: "A atenção dada à precisão terminológica deve caraterizar a preparação profissional de todos: a relação clara entre a nomenclatura e o objeto e/ou conceito são a garantia de uma comunicação correta, no respeito pelo Outro, competente e urgente".

FRÉJAVILLE, R. M. A Terminologia: um instrumento ao serviço da inovação pedagógica no Espaço Europeu do Ensino Superior 
Linha D’Água (Online), São Paulo, v. 33, n. 1, p. 167-185, jan.-abr. 2020

mais conhecidas, como a memória auditiva, visual e olfativa, são imprescindíveis para a compreensão e a prática do mundo usual. Mas, entre muitas outras, ainda podemos destacar: a memória associativa, útil para as atividades de tradução (associação de um conceito a termos de línguas diferentes, por exemplo); a memória processual, necessária para reforçar as ações de rotina (a repetição de ações); a memória semântica, útil para a compreensão do mundo que nos rodeia (que pode reforçar o trabalho terminológico e tem papel central no funcionamento cognitivo); a memória episódica, útil para situar ações vividas em determinado tempo e espaço; a memória implícita, necessária para a aquisição de novos conhecimentos semânticos e para criar rotinas nessa aquisição ${ }^{13}$; e a memória explícita, muito importante para a consciencialização de ações vividas e de conhecimentos.

A memória é, pois, indispensável em todas as aprendizagens e tem em geral a função de codificação, de classificação e de recuperação de informação. Entre a memória e a Terminologia as afinidades são percetíveis.

\section{Conclusão}

Para além de todas as considerações que tecemos sobre o projeto de novo paradigma educacional europeu e sobre os mecanismos existentes e as experiências realizadas, resta-nos tecer algumas considerações sobre os elementos que estruturam este novo paradigma educacional: programa, pedagogia, avaliação. O programa é o contrato com o aluno que descreve os conhecimentos a adquirir; a pedagogia é o processo que permite ao aluno adquirir competências, e a avaliação é o meio para verificar a aquisição dos conhecimentos (em auto e heteroavaliação). Três elementos simples que provocam ainda algumas reticências no meio universitário francês. $\mathrm{Na}$ verdade, não se trata de um sistema tripartido, mas completamente imbricado de forma que o que se produz no cimo da escala terá repercussões no final do processo. Em geral, o nosso sistema de ensino universitário francês preocupa-se muito com o programa e muito pouco com a pedagogia (formação por competências) e

13 Incitamos os nossos alunos de LEA/português a utilizar este tipo de memória para os levar a formar as representações e os conhecimentos automaticamente.

FRÉJAVILLE, R. M. A Terminologia: um instrumento ao serviço da inovação pedagógica no Espaço Europeu do Ensino Superior 
Linha D’Água (Online), São Paulo, v. 33, n. 1, p. 167-185, jan.-abr. 2020

com o sistema de avaliação que não passa muitas vezes de uma docimologia com pouco enfoque na avaliação formativa e sumativa.

Em síntese, o novo paradigma implica uma mudança de postura do professor e do aluno. Esse último deve estar no centro da sua aprendizagem. O novo paradigma implica também a construção de mecanismos de ativação das diferentes categorias de memória e a utilização de estratégias de desenvolvimento de uma metamemória com o apoio da metodologia terminológica. A Terminologia será também fundamental na construção da arquitetura do projeto pedagógico, nomeadamente, na elaboração do programa que deverá privilegiar os conhecimentos a adquirir, mas também a praticar (o saber agir), na pedagogia como processo que vai permitir ao aluno adquirir uma formação por competências e na avaliação em adequação com as duas fases do processo.

Concluímos com as afirmações de Paulo Feytor Pinto e Sílvia Melo-Pfeifer (2018) que nos parecem de bom augúrio: "Se, no século XX, uma língua precisava de um exército, na sociedade global da escrita, uma língua precisa sobretudo de um sistema educativo. A educação é o ‘braço armado’ da política linguística” (PINTO; MELO-PFEIFER, 2018, p. 14)

\section{Referências}

Cadre Européen commun de référence pour les langues : apprendre, enseigner, évaluer -Volume complémentaire avec de nouveaux descripteurs, Programme des Politiques linguistiques, Division des Politiques éducatives, Service de l'Education, Conseil de l'Europe, 2018, https:// rm.coe.int/cecr-volume-complementaire-avec-de-nouveaux-descripteurs/16807875d5

FREJAVILLE, R.M., SILVA, A., DUMONT, R. Le domaine du patrimoine : nouvelle dimension des formations supérieures pour la mutation et l'internationalisation des Universités. Quels atouts pour la valorisation des langues et de la terminologie? Terminologia para a normalização e terminologia para a internacionalização, XIII Jornada REALITER, Barcelona, 2017.

LESSARD, Cl., BOURDONCLE, R.. Qu'est- ce qu'une formation professionnelle universitaire? Conceptions de l'université et formation professionnelle. Revue française de pédagogie, $\mathrm{n}$. $139,2002$.

FRÉJAVILLE, R. M. A Terminologia: um instrumento ao serviçơ da inovação pedagógica no Espaç̦o Europeu do Ensino Superior 
Linha D’Água (Online), São Paulo, v. 33, n. 1, p. 167-185, jan.-abr. 2020

PINTO, P.F., MELO-PFEIFER, S. Politicas linguísticas em português. Lisboa: LIDEL, 2018

SCHÄDLICh, B. Médiation linguistique et didactique du plurilinguisme et du pluriculturalisme. In : MEDHAT-LECOCQ, H. ; DELOMBERA, N. ; SZENDE, T. (Orgs.). Traduction et apprentissage des langues:entre médiation et remédiation. Paris: Archives Contemporaines Editions, 2016.

ZANOLA, M. T. Che cosè la terminologia. Roma: Carocci editore, 2018.

Recebido: $16 / 12 / 2019$.

Aprovado: 22/02/2020.

FRÉJAVILLE, R. M. A Terminologia: um instrumento ao serviço da inovação pedagógica no Espaço Europeu do Ensino Superior 